\title{
Maternal determinants affecting perinatal mortality: a multivariate statistical approach
}

\author{
Manish Agrawal ${ }^{1 *}$, Kriti Bhatnagar ${ }^{2}$

\begin{abstract}
${ }^{1}$ Department of Pediatrics, Muzaffarnagar Medical College and Hospital, Muzaffarnagar, Uttar Pradesh, India ${ }^{2}$ Department of Obstetrics and Gynecology, Muzaffarnagar Medical College and Hospital, Muzaffarnagar, Uttar Pradesh, India
\end{abstract}

Received: 07 January 2017

Accepted: 04 February 2017

\section{*Correspondence:}

Dr. Manish Agrawal,

E-mail: mameerut@yahoo.com

Copyright: ( $)$ the author(s), publisher and licensee Medip Academy. This is an open-access article distributed under the terms of the Creative Commons Attribution Non-Commercial License, which permits unrestricted non-commercial use, distribution, and reproduction in any medium, provided the original work is properly cited.

\begin{abstract}
Background: India has made considerable progress over the last two decades in the area of maternal and child health, through innovative and comprehensive health packages that covers the spectrum of Reproductive Child Health $(\mathrm{RCH})$. Awareness of the special vulnerability of the cohort of mothers with 'high risk factor' has led to the popular recognition of 'risk approach', involving the optimal use of existing $\mathrm{MCH}$ services, providing essential obstetrical care for all with early detection of complications and emergency services for those who need it, thus reducing the need for intensive care along with reduction in perinantal mortality. The objective was to assess the prevalence of various maternal risk factors in pregnant women in hospital admissions and their correlation with perinatal mortality. Methods: The present study was carried out on 2050 consecutive deliveries from 1st April 2015 to 31st March 2016 at Department of Obstetrics and Gynecology and Department of Pediatrics, Muzaffarnagar Medical College, Muzaffarnagar Uttar Pradesh, India. All the pregnant women were interviewed and examined in detail at the onset of labor regarding various biosocio-economic characteristics, history of past and present medical and obstetrical complications.
\end{abstract}

Results: The PNMR (93.66/1000 birth) observed in present study was still at a higher level and comparable to that in other studies done by various authors in past in this region. A significantly higher PNMR was observed with increase in maternal age and parity ( 3 times higher PNMR at $>35$ years and $2 \frac{1}{2}$ times higher PNMR at parity $>5$ ). Similarly, medical illnesses ( 3 times higher PNMR) and obstetrical complications (1.5 times higher PNMR) during present pregnancy were showing significant effect on perinatal outcome. In a multivariate analysis, residence (rural /urban), place and number of antenatal visits, gestational age and type of delivery remained as most significant maternal risk factors $(p<0.005)$ after multiple logistic regression of other factors viz. maternal age, height, weight, parity, education, socio-economic status and antepartum anemia.

Conclusions: It is heartening to observe that highest risk is associated with simple and easily identifiable factors like, unbooked cases, $<3$ antenatal visits, severe anemia, age $>35$ years, parity $>5$, weight $<40 \mathrm{~kg}$, height $<140 \mathrm{~cm}$, poor dietary calories, medical and obstetrical complications. These can identified from history only by grass root workers like traditional birth attendants and even elderly female family members. These risk determinants, labeled as simple but 'high' high risk are associated with poor perinatal outcome. If these factors are timely identified at community level and appropriately referred by grass root workers, it will significantly reduce perinatal mortality and improve neonatal survival.

Keywords: High risk approach, Maternal risk factors, Perinatal mortality, Neonatal mortality 


\section{INTRODUCTION}

It is painful to know that even after advancement of medical science to a great extent, we in India still lose approximately 1 million out of 26 million infants born every year at a rate of 40/1000 live births. Approximately $70 \%$ of these infants die within first 4 weeks in neonatal period (0.76 million) at a rate of 28/1000 live births and out of these roughly $80 \%$ of neonatal deaths ( 0.6 million) occur within $1^{\text {st }}$ week of their life in early neonatal period. ${ }^{1,2}$

India has made considerable progress over the last two decades in the area of maternal and child health, through innovative and comprehensive health packages that covers the spectrum of reproductive child health $(\mathrm{RCH})$. Newborns however have missed out on the attention. The neonatal mortality rate (NMR) has declined at a slower pace compared to that of under-five mortality rate (U5MR). Despite the fact that maternal mortality has gone down considerably in recent past, perinatal mortality has attained a plateau at a higher level after a marginal decline over past two decades. Awareness of the special vulnerability of the cohort of mothers with 'high risk factor' has led to the popular recognition of 'risk approach'. The risk approach involves the optimal use of existing $\mathrm{MCH}$ services providing essential obstetrical care for all with early detection of complications and emergency services for those who need it, thus reducing the need for intensive care along with reduction in perinatal mortality..$^{3,4}$

Periodical statistical information of the maternal risk factor provides a comprehensive idea of the magnitude of the problem, change in trend and effect of previous studies in the concerned community.

\section{METHODS}

With this view, the present study was carried out on 2050 consecutive deliveries from $1^{\text {st }}$ April 2015 to $31^{\text {st }}$ March 2016 at Department of Obstetrics and Gynecology and Department of Pediatrics, Muzaffarnagar Medical College, Muzaffarnagar, Uttar Pradesh, India. All the pregnant women were interviewed and examined in detail at the onset of labor regarding various biosocio-economic characteristics, history of past and present medical and obstetrical complications.

The statistical analysis consisted of comparison and association of perinatal mortality with various biosocial, antenatal, intrapartum and postnatal variables.

A univariate analysis was done using 'EPI-INFO' software package designed by WHO, Geneva. Chisquare and fisher-exact tests were done as a test of significance of difference between various maternal risk factors and perinatal mortality.
Then risk factors showing statistically significant relation with outcome of delivery were selected for 'multivariate analysis' to assess their relation with perinatal mortality. The multivariate analysis was done using 'MULTLR' (multiple logistic regression by unconditional and conditional methods) software package designed by Epidemiology and Biostatistics unit of Ludwig Institute for cancer research- SP branch.

\section{RESULTS}

Out of total 2050 births registered, there were 1992 singleton deliveries $(97.17 \%)$ and 58 twin deliveries $(2.83 \%)$. Overall perinatal mortality rate (PNMR) was 93. 66/1000 births, comprising of Still birth rate of $59.03 / 1000$ births and Early neonatal mortality rate of 34.63/1000 births). In twin pregnancies a perinatal mortality rate of 241.3/1000, still birth rate of 103.4 and early neonatal mortality rate of $137.9 / 1000$ was observed. these values are approximately three times higher than singleton deliveries. Approximately $71 \%$ of total subjects were high risk mothers having perinatal mortality rate of $143.9 / 1000$ as compared to perinatal mortality rate of $47.7 / 1000$ in low risk mothers (Table 1).

Table 1: Basic information.

\begin{tabular}{|lll|}
\hline $\begin{array}{l}\text { Characteristics } \\
\text { Total birth registered after } \\
\text { delivery }\end{array}$ & 2050 & NA \\
\hline Singleton deliveries & 1992 & $97.17 \%$ \\
\hline Twin deliveries & 58 & $2.83 \%$ \\
\hline Still birth & 121 & $59.03 / 1000$ birth \\
\hline Early neonatal mortality & 71 & $34.63 / 1000$ birth \\
\hline Perinatal mortality & 192 & $93.66 / 1000$ birth \\
\hline High risk mothers & 1451 & $70.78 \%$ \\
\hline
\end{tabular}

A highly statistically significant relation of increase in maternal age and parity was observed with higher perinatal mortality and morbidity. The safest age groups in terms of perinatal mortality (PNMR) and early neonatal morbidity (ENMB) were 25-29 and 20-24 years respectively. Similarly maternal weight $<45 \mathrm{Kg}$ and height $<140 \mathrm{~cm}$, maternal education (below high school), rural residence, occupation (non-skilled workers), low socio-economic status, poor dietary caloric/protein intake, anemia (especially at $\mathrm{Hb} \%<10 \mathrm{gm} \%$ and very significantly below $7 \mathrm{gm} \%)$, short birth spacing $(<3$ years), all were found to be statistically significant in relation to higher perinatal mortality and morbidity (Table 2).

After multiple logistic regression, residence (rural /urban), place and number of antenatal visits, gestational age and type of delivery remained as most significant maternal risk factors $(\mathrm{p}<0.005)$ after multiple logistic regression of other factors viz. maternal age, height, weight, parity, education, socio-economic status and antepartum anemia (Table 3). 
Table 2: Univariate analysis.

\begin{tabular}{|c|c|c|c|c|c|c|c|}
\hline \multirow{2}{*}{ Factor } & \multirow{2}{*}{$+/-$} & \multirow{2}{*}{ Total No. } & \multicolumn{2}{|c|}{ Perinatal Mortality } & \multirow{2}{*}{ Odd's ratio } & \multirow{2}{*}{$\mathrm{X}^{2}$} & \multirow{2}{*}{$P$ value } \\
\hline & & & No. & Rate & & & \\
\hline \multirow{2}{*}{ Age $<20$} & + & 113 & 9 & 80 & \multirow{2}{*}{0.83} & \multirow{2}{*}{0.28} & \multirow{2}{*}{0.599} \\
\hline & - & 1937 & 183 & 94 & & & \\
\hline \multirow{2}{*}{ Age $>35$} & + & 108 & 28 & 260 & \multirow{2}{*}{3.79} & \multirow{2}{*}{36.8} & \multirow{2}{*}{0.000} \\
\hline & - & 1942 & 164 & 84 & & & \\
\hline \multirow{3}{*}{ Parity } & 1 & 891 & 84 & 94 & \multirow{3}{*}{ NA } & \multirow{3}{*}{9.64} & \multirow{3}{*}{0.008} \\
\hline & $2-4$ & 1088 & 94 & 86 & & & \\
\hline & $\geq 5$ & 71 & 14 & 197 & & & \\
\hline \multirow{2}{*}{ Religion (Hindu) } & + & 1759 & 161 & 92 & \multirow{2}{*}{0.85} & \multirow{2}{*}{0.66} & \multirow{2}{*}{0.416} \\
\hline & - & 291 & 31 & 106 & & & \\
\hline \multirow{2}{*}{ Height $<140 \mathrm{~cm}$} & + & 102 & 20 & 196 & \multirow{2}{*}{2.52} & 1326 & 0000 \\
\hline & - & 1948 & 172 & 88 & & 15.20 & 0.000 \\
\hline & + & 168 & 30 & 179 & 231 & 1554 & 0000 \\
\hline Welght $<40 \mathrm{~kg}$ & - & 1882 & 162 & 86 & 2.31 & 15.54 & 0.000 \\
\hline & + & 511 & 81 & 158 & & 327 & 0.000 \\
\hline Residence (rural) & - & 1539 & 111 & 72 & 2.4 & 32.1 & 0.000 \\
\hline Education & Illiterate+ prim & 1307 & 158 & 128 & 221 & 793 & \\
\hline & $\geq$ High school & 239 & 14 & 59 & 2.21 & 1.93 & 0.005 \\
\hline Diet calories (poor) & + & 447 & 83 & 186 & & & 0.000 \\
\hline Diet calories (poor) & - & 1603 & 109 & 68 & 3.13 & $5 \% .00$ & 0.000 \\
\hline & $\leq 8.0$ & 54 & 13 & 241 & & & \\
\hline $\mathrm{Hb}(\mathrm{gm} / \mathrm{dl})$ & $8.1-9.0$ & 44 & 7 & 159 & NA & 31.59 & 0.000 \\
\hline & $>9.0$ & 1406 & 85 & 60 & & & \\
\hline Unbooked & + & 817 & 157 & 192 & & & 0.000 \\
\hline & - & 1233 & 35 & 28 & 8.3 & 153.4 & 0.000 \\
\hline & 0 & 317 & 76 & 236 & & & \\
\hline Anenatal visits & $1-2$ & 217 & 49 & 226 & NA & 166.7 & 0.000 \\
\hline & $\geq 3$ & 1516 & 67 & 44 & & & \\
\hline IFA & $0-60$ & 452 & 94 & 208 & 4.94 & & \\
\hline Tablets & $\geq 120$ & 990 & 50 & 50 & 4.94 & 85.53 & 0.000 \\
\hline Bad Obstetric history & + & 202 & 11 & 54 & 0.5 & 4.5 & 0.040 \\
\hline & - & 1848 & 181 & 98 & 0.5 & & \\
\hline & + & 67 & 17 & 254 & & 20.9 & 0.000 \\
\hline Mledical illness & - & 1983 & 175 & 88 & 3.5 & 20.9 & 0.000 \\
\hline & + & 1009 & 114 & 113 & 1.57 & 8.74 & 0.003 \\
\hline Ubstetrical complication & - & 1041 & 78 & 75 & 1.51 & 8.14 & 0.003 \\
\hline & Normal & 1342 & 122 & 91 & & & \\
\hline Delivery type & Forceps & 144 & 9 & 62 & NA & 3.16 & 0.205 \\
\hline & Caesarean & 564 & 61 & 108 & & & \\
\hline
\end{tabular}

Table 3- Multiple logistic regression.

\begin{tabular}{|llllllll|}
\hline Factors & Coefficient & S.E & Z-score & P-value & O.R. & Lower & Upper \\
\hline Residence & 0.5738 & 0.1900 & 3.0194 & 0.0025 & 1.775 & 1.223 & 2.576 \\
\hline Maternal Age & -0.0338 & 0.0215 & -1.5764 & 0.1149 & 0.967 & 0.927 & 1.008 \\
\hline Weight & 0.0080 & 0.0145 & 0.5484 & 0.5834 & 1.008 & 0.980 & 1.037 \\
\hline Height & 0.0075 & 0.0175 & 0.4260 & 0.6701 & 1.008 & 0.973 & 1.0430 \\
\hline Parity & 0.0579 & 0.0815 & 0.7096 & 0.4779 & 1.060 & 0.903 & 1.243 \\
\hline Gestation & 0.3068 & 0.0279 & 11.0122 & 0.0000 & 1.359 & 1.287 & 1.435 \\
\hline Education & 0.0787 & 0.0940 & 0.8366 & 0.4028 & 1.082 & 0.900 & 1.301 \\
\hline Income & -0.0002 & 0.0002 & -1.2208 & 0.2222 & 1.000 & 0.999 & 1.000 \\
\hline Occupation & 0.1092 & 0.1780 & 0.6134 & 0.5396 & 1.115 & 0.787 & 1.581 \\
\hline AN visits & 0.5049 & 0.0730 & 6.9215 & 0.0000 & 1.657 & 1.436 & 1.912 \\
\hline Place of ANC & -0.4078 & 0.0632 & -6.4485 & 0.0000 & 0.665 & 0.588 & 0.753 \\
\hline Hb \% ( mother ) & 0.0182 & 0.0141 & 1.2947 & 0.1954 & 1.018 & 0.991 & 1.047 \\
\hline Delivery Type & -0.2899 & 0.0950 & -3.0505 & 0.0023 & 0.748 & 0.621 & 0.902 \\
\hline Constant & -11.7089 & 2.5956 & -4.5110 & 0.0000 & & & \\
\hline
\end{tabular}




\section{DISCUSSION}

The PNMR (93.66/1000 birth) observed in present study was still at a higher level and comparable to that in other studies done by various authors in past in this region. ${ }^{4-7}$

The high PNMR found in present study was multifactorial, important reasons being:

- $\quad$ An extended PNMR was taken in this study as used by most of the authors ${ }^{8}$ and national neonatology forum presently, thus including most of more preterms with poor survival rates $(<30 \%$ at $<28$ weeks).

- $\quad$ Higher percentage of still births (63.02\% of PNMR) due to, $70.78 \%$ of high risk mothers in our study.

- Major portion of PNMR (81.77\%) was contributed by unbooked complicated emergency cases (approx. $40 \%$ ).

- Almost a half of PNMR (42.19\%) was contributed by rural admission (1/ $4^{\text {th }}$ of total cases).

- Again it is well known fact that statistics from large teaching hospitals though accurate, give a falsely high PNMR, as these hospitals have to treat serious and late referrals often from far off rural places. ${ }^{9}$

\section{Evaluation of various maternal factors in relation to perinatal mortality}

A significantly higher PNMR was observed with increase in maternal age and parity ( 3 times higher PNMR at $>35$ years and $21 / 2$ times higher PNMR at parity $>5$ ), as seen in other studies also. ${ }^{2,10-16}$ However, in contrast to some other authors, there was only slightly higher PNMR (not statistically significant) in teenage mother $(<20$ year age) and primipara, as also supported by others., , $^{2-7,16-19}$ The safest age group was found to be between 25-29 years of age, against $20-24$ years in other studies. ${ }^{10-16}$

Six and half times higher PNMR was observed in unbooked cases than booked cases and no significance difference in PNMR was observed in mothers having 0 or 1-2 antenatal visits (51/2 times PNMR than who took $\geq 3$ antenatal Visits). Similarly 4 times higher PNMR was seen in mothers receiving $<60$ iron- folic acid tablets than who took $>120$ tablets. , $^{2-7,15,16}$

No significant relation of religion was observed with PNMR as against some previous studies. ${ }^{14,20-23}$ While more than 2 times higher PNMR was observed in rural and in illiterate and even in primary educated mothers than in high school and above educated mothers. ${ }^{13,15,16,22}$ A more than twice PNMR was found in mother having $<40 \mathrm{~kg}$ weight and <140 cms height. ${ }^{15,16}$

Three times higher PNMR was seen in mothers having poor dietary calories ( $<2200 \mathrm{kcal} / \mathrm{day}){ }^{5,22}$ A 4 times higher PNMR was observed in mothers having $\mathrm{Hb} \% \leq 8$ gm $\%$ and it reduced to $2 \frac{1}{2}$ times higher PNMR with only $1 \mathrm{gm} \%$ increase in $\mathrm{Hb} \%$ (8.1-9.0 gm 5\%). ${ }^{7,10,12}$
Similarly, medical illnesses (3 times higher PNMR) and obstetrical complications (1.5 times higher PNMR) during present pregnancy were showing significant effect on perinatal outcome. ${ }^{3-7,10,15,16}$ While in contrast several studies past bad obstetric history (e.g. previous caesarean, abortion $>2$ and previous perinatal death) didn't show any statistically significant relation with poor perinantal outcome. . $^{3-15,16}$ Forceps delivery showed slightly lower and caesarean slightly higher PNMR than normal delivery but it was not statistically significant.

In a multivariate analysis, residence (rural /urban), place and number of antenatal visits, gestational age and type of delivery remained as most significant maternal risk factors $(p<0.005)$ after multiple logistic regression of other factors viz. maternal age, height, weight, parity, education, socio-economic status and antepartum anemia.

\section{CONCLUSION}

It is heartening to observe that highest risk is associated with simple and easily identifiable factors like, unbooked cases, <3 antenatal visits, severe anaemia, age $>35$ years, parity $>5$, weight $<140 \mathrm{cms}$, poor dietary calories, medical and obstetrical complications. These can identified from history only by grass root workers like traditional birth attendants and even elderly female family members. These risk determinants, labelled as simple but 'high' high risk are associated with poor perinatal outcome. If these factors are timely identified at community level and appropriately referred by grass root workers, it will significantly reduce perinatal mortality and improve neonatal survival. Simple training of these grass root workers for identification of these simple but 'high' high risk determinants should form an integral part of I.E.C. (Information Education and Communication) activities.

\section{Funding: No funding sources \\ Conflict of interest: None declared \\ Ethical approval: The study was approved by the Institutional Ethics Committee}

\section{REFERENCES}

1. State of India's newborns (SOIN) 2014- a report. In: Zodpey $\mathrm{S}$ and Paul VK. Eds. Public Health Foundation of India, All India Institute of Medical Sciences and Save the Children. New Delhi, India.

2. World bank data on NMR: 2011-15.

3. WHO (2014). The risk approach in public health care, WHO public health paper No.96: 2014.

4. Hobel CJ, Myvarinen MA, Odada DM and oH W. Prenatal and intrapartum high risk screening I prediction of high risk neonate. Am J Obstet Gynecol. 1973;117:1-9.

5. Bajpai PC, Kutty D, Rajgopalan KC, Wahal KM. Observations on perinatal mortality. Ind pediatr. 1996;3:83-98. 
6. Misra PK, Bajpai PC, Tripathi TK, Gupta R, Kutty D. Perinatal mortality: a hospital study, Ind Pediatr. 1973;10:545-50.

7. Malik GK, Misra PK. Observations on perinatal mortality. Ind. Med Coll Gazt. 1980; CXIV:401-4.

8. Anand R. Antenatal and intrapartum high risk scoring in relation to neonatal outcome. Thesis for MD (Paediatrics), University of Lucknow. 1981.

9. Meharban S. Hospital based date on perinatal and neonatal mortality in india. Special article. Ind Pediatr. 1986;23:327-34.

10. Bhave SA. Trends in perinatal and neonatal mortality and morbidity in india. Ind Pediatr. 1989;26:1094-9.

11. Puri RK, Verma TC, Choudhary P, Nalini P, Srinivasan S. Perinatal mortality incidence and effect of various maternal factors. Indian $\mathrm{J}$ Pediatr. 1981;49:297-304.

12. Bhandari B, Mandowara SL. Perinatal mortality in south east Rajasthan. Ind Pediatr. 1983;2:595-602.

13. Shah U. Perinatal mortality in India: Can it be reduced through primary health care? Indian $\mathrm{J}$. Pediatr. 1986;53:327-34.

14. Ramji S. Socio- economic and environmental determinants of perinatal and neonatal mortality in India. Ind Pediatr. 1989;26:1100-5.

15. Saran N. An epidemiological study of PNM with special reference to high risk approach in a rural community. Thesis of MD (SPM), University of Lucknow. 1990.
16. Belizan JM. Maternal Risk factors affecting newborn infants. International child Health. 1993;30-40.

17. ICMR (1994). A multicentric collaborative study on $\mathrm{MCH}$ care utilizing high risk approach strategy at PHC's (An ICMR taskforce study, 1994).

18. Berkowitz GS. Delayed child bearing and the outcome of pregnancy. Nat Engl J Med Coll. 1990;322(10):659-64.

19. Haines $\mathrm{CH}$. Neonatal outcome and its relationship with maternal age. Aust NZ J Obstet Gynaecol. 1991;31(3):209-12.

20. Ekblad U, Vilpa T. Pregnancy in women over forty. Ann Chir Gynaecol Suppl. 1994;208:68-71.

21. Who (1980). Towards a better future. World Health organization Geneva.

22. Alexander GR, Baruffi G. Multiethnic variations in the pregnancy outcome of military dependents. Am J Pub Health. 1993;83(12):1721-5.

23. Mittal M, Ketkar M. A study of perinatal and neonatal mortality in Indore. Indian J Pub Health. 1970;14:23-30.

24. Memeria CB. 1981, India's population problems. 2nd Ed. kitab Mahal, Allahabad, U.P. (India).

Cite this article as: Agrawal M, Bhatnagar K. Maternal determinants affecting perinatal mortality: a multivariate statistical approach. Int J Reprod Contracept Obstet Gynecol 2017;6:1052-6. 